\title{
Career Development of Range Conservationists in Their First Three Years with the Forest Service
}

\author{
JAMES J. KENNEDY
}

\author{
Abstract
}

This paper examines early career development of range conservationists, relative to their forester and wildlife biologist colleagues, in 2 western Forest Service Regions. Perception and acceptance of agency values, satisfaction with range profession and job choices, and long-term career commitments are a few subjects studied. Results show the majority of range conservationist recruits and their colleagues fitting into a long-term commitment to their professions and the Forest Service. Still, about 20\% were experiencing initial career adjustment problems.

About half the sample were women, and some important female/male differences exist. The greatest differences, however, were observed between professional-types. Range conservationists and foresters (regardless of sex) were generally adapting to a career in the Forest Service more easily than biologists. Range conservationists stood out in their desire for future Forest Service employment when selecting a range science major and belief that their "professional competence" was valued by the Forest Service.

Key words: employment, range conservationist, careers

Range management graduates join organizations like the Forest Service understanding much about natural resources and willing to take responsibility in their management. But there's another valuable resource professional recruits to organizations must manage well to be successful and productive natural resource managerstheir careers.

Great personal and social costs occur when well-trained, gifted, natural resource professionals are not successful in their careers. Individuals and their families suffer, organizations that employ them operate less efficiently, and natural resources are less well managed. For an issue as important as career development, it's surprising that the universities training natural resource managers and the organizations employing them do not invest more effort to understand how (and how not) professional careers unfold to be successful and productive.

Cursory examination of the Journal of Range Management locates many articles discussing the proper education and performance of professional range managers (e.g., Tisdale 1956, Morris 1961, Arnold 1970, or Box 1974). Most of these are personal opinions of respected members of the profession, a few base their insights on empirical evidence (e.g., Cook and Bonham 1974, Kienast and Scifres 1973, Nortan and Eastman 1981). Given the shortage of good empirical studies, career development of the range management profession will have to build upon research of other professionals-such as Dalton et. al's (1977) study of engineers and scientists.

This paper examines the early careers of about 27 range conservationists (hereafter called range-cons) recently hired by the Forest Service. The research (Kennedy and Mincolla 1982) is based on the career development concepts of Schein (1978) and employs careerstage perspectives of Dalton et al. (1977), Vaillant (1977) or Levinson et al. (1978). Elements of these career development theories will be described below when applicable to the study's findings. For a good introduction to career development concepts see Hall (1976) and, especially, Schein (1978).

The author is with the College of Natural Resources, Utah State University, Logan 84322-5200.

This project was jointly funded by the USDA-Forest Service and the Utah Agricultural Experiment Station, Maclntire Stennis Project 712 (Journal Paper 2905).

Manuscript accepted 8 December 1986.
The Study

In fall 1981 the USDA-Forest Service (USFS), and the Utah State University Agricultural Experiment Station collaborated to study the career development of entry-level range-cons, foresters, and wildlife/fisheries biologists (hereafter labeled WL/F biologists) hired by USFS Regions 4 and 6 between 1978-81. The entry-level career stage is defined as $0-3$ years in a permanent appointment. USFS Region 4 consists of the intermountain states of Utah, Nevada, southern Idaho, and western Wyoming. Timberoriented Region 6 (Oregon and Washington) provides a contrast to the range-wildlife-watershed focus of Region 4 . Region 6 also has the largest numbers of employees of any USFS region.

To obtain a different perspective of young professionals' attitudes and performance, their immediate supervisors were also sampled. Questionnaire return rates were $81 \%$ for young professionals (hereafter called YPROS) and $71 \%$ for their immediate supervisors (SUPERS). Such return rates yielded about a 50\% sample of YPROS and SUPERS. About half the YPRO population and sample were women.

Region 4 and 6 populations were stratified by professional-type and randomly sampled within strata to ensure range-cons, WL/F biologists, and foresters were adequately represented. Twentyseven range-cons (for a $96 \%$ completion-rate) returned both volumes of the questionnaire. Twenty-one were from Region 4 and 6 from Region 6 . Forty-eight percent of the range-cons returning both volumes of the questionnaire were women.

USFS Regions 4 and 6 were selected because of interest in their human resources and willingness to cooperate in this research. The $50 \%$ sample is believed adequate to make inference to these 2 regions. No pretense is made that the sample is a good indicator of larger Forest Service populations. Our research is seen only as an important and pathbreaking case study of 2 large USFS Regions that together employ about $40 \%$ of all range-con professionals and $26 \%$ of all foresters and WL/F biologists in the agency (Akins et al. 1982).

A complete description of the study's theoretical foundation, hypotheses tested, and questionnaires used is available in Mincolla and Kennedy (1982). Results presented here will focus on rangecons, with comparisons to their forester or WL/F biologist colleagues where notable differences occur. Many findings like mentoring or dual-career issues with working spouses are omitted here - but are available in Kennedy and Mincolla (1982). The findings (below) begin with range-cons' selection of a university major leading to their permanent USFS appointment, examine how (and how not) range-cons are fitting into that job, and finish with a look at commitment to the range management profession and the USFS organization.

Selecting a Range Science Major and Getting a Forest Service Job

Most range-cons (73\%) had decided to pursue their current career and were enrolled in an appropriate college major at age 20. Important motivations for such a career choice were explored in an open-ended question. Their personal replies easily coded into 6 categories, with $90 \%$ of range-cons career motivation being in the following 4 (in descendent order of popularity):

1. Geographic preference for working in a certain part of western USA. 
2. Practical rewards of finding dependable, reasonably paid employment.

3. Desire to work in/with range and natural environments.

4. Work/career that's enjoyable, challenging and/or rewarding. A Chi-square $\left(X^{2}\right)$ value of 25.5 (with 12 degrees of freedom) illustrated that there was a great difference in career motivation between professional-types $(p<.01)$. Range-cons were like their forester colleagues in selecting a career that would allow them to live in a certain geographic area (namely, Region 4 range-cons wanted to work and recreate in Intermountain West; Region 6 foresters felt the same about Oregon and Washington). Second most common career selection reasons for range-cons (third for foresters) were practical considerations like, ". . . had a better chance of getting a job with my major...", or “... was attracted to pay and job security of government work..."The WL/F biologists stood apart in rarely giving geographic or practical job-related motivation for selecting their careers. Their major motivation fell into a "concern for resources" category that included many idealistic statements about wildlife resources being well managed and protected. Such motivation ranked only fourth for foresters and sixth for range-cons.

From general career motivation, the questionnaire focused on when range-cons decided they wanted to work for the USFS, asking, "Was the U.S. Forest Service, as a possible place for you to work, an important influence when you made the decision to pursue a natural resource occupation?" Respondents could check a scale of 6 replies ranging from "extremely important" through "neutral" to "no importance" at the opposite end of the continuum. Notice the difference in replies between range-cons, foresters and (especially) $\mathrm{WL} / \mathrm{F}$ biologists in Table 1 . Seventy-one percent of

Table 1. Importance of USFS as a future source of employment when selecting a college major.

\begin{tabular}{lccc}
\hline \hline & \multicolumn{3}{c}{ Response by Professional-Type: } \\
\cline { 2 - 4 } Response Scale: & $\begin{array}{c}\text { Range-cons } \\
(\mathrm{n}=27)\end{array}$ & $\begin{array}{c}\text { Foresters } \\
(\mathrm{n}=43)\end{array}$ & $\begin{array}{c}\text { WL/F biologists } \\
(\mathrm{n}=38)\end{array}$ \\
\hline Of no importance & $7 \%$ & $13 \%$ & $40 \%$ \\
Very unimportant & $11 \%$ & $2 \%$ & $15 \%$ \\
Unimportant & $7 \%$ & $8 \%$ & $5 \%$ \\
Neutral & $4 \%$ & $21 \%$ & $18 \%$ \\
Important & $26 \%$ & $21 \%$ & $12 \%$ \\
Very Important & $37 \%$ & $24 \%$ & $10 \%$ \\
Extremely Important & $8 \%$ & $11 \%$ & - \\
& $100 \%$ & $100 \%$ & $100 \%$ \\
\hline
\end{tabular}

${ }^{\circ}$ Chi square $=X^{2}=31.0$ with $12 \mathrm{df}$. and significant at $<.01$.

range-cons and $56 \%$ of foresters recalled future USFS employment an important to extremely important consideration when selecting their profession (at about age 20). This may illustrate a form of USFS precommitment several years prior to accepting a permanent job. Only $22 \%$ of WL/F biologists were very interested in future USFS employment when choosing their college major. These differences are significant $(p<.01)$.

All range-cons received their permanent USFS appointment since 1978. They had much less graduate education entering that job than their forester and WL/F biologist colleagues. Only $11 \%$ of range-cons completed MS (or higher) degrees-while 23\% of foresters and $68 \%$ of WL/F biologists did so $(p=.01)$. They also entered permanent USFS employment with considerable professional job experience $-84 \%$ having had 2 or more temporary jobs in their professional area. When surveyed in fall 1981, most range-cons (85\%) were still on their first permanent USFS assignment.

On a seven-point scale they ranged from extremely high to extremely low, with a neutral position, range-cons rated overall job satisfaction for their first permanent USFS job rather high. About $82 \%$ marked overall job satisfaction in the 3 high ranges; $78 \%$ said that job had positive to extremely positive impacts on commitment to their professions; even more, $(81 \%)$ rated its impact on their commitment to the USFS in that positive to extremely positive range. There were no significant $X^{2}$ differences $(p \leq .05)$ in first permanent job impacts between range-cons, WL/F biologists or foresters, but women in these 3 professional-types experienced significantly lower "overall job satisfaction" $(p=.01)$ and less positive impact of their first permanent job on "commitment to the USFS" $(p=.02)$ than their male colleagues.

\section{Fitting Oneself into the Forest Service Organization}

Fitting into their first USFS permanent job requires professional recruits to get reasonably well oriented in their first months and begin to be productive (Van Maanen 1977, Schein 1978). Otherwise recruits may experience confusion, disorientation, and alienation from their profession and/or the USFS. How well range-cons are accomplishing a fit between themselves, their job requirements, USFS values, etc., is the subject of next sections.

\section{Description of Job Responsibilities}

Working "out-of-doors with the resource" dominated the job motivations of the young professionals studied. Field concepts and techniques were also a major focus of their college education. Yet very few YPROS sampled spent over 50\% of their time in the field during the initial 3 years.

Range-cons spent an average of $15 \%$ of their time in the field and $15 \%$ in technical officework. After a mean of 2 years in the USFS, their primary job activity was planning/administration (40\%) and coordinating between the USFS and their clients or other agencies (26\%)-work arenas usually requiring good people and political skills. The remaining $4 \%$ of their time was in internal USFS multiple-use coordination.

Foresters were doing the most fieldworld (35\%)-with $23 \%$ of their time in technical office work and $40 \%$ in planning. WL/F biologists also experienced twice the fieldwork (33\%) as rangecons, $8 \%$ of their time was officework, $31 \%$ planning, 22 internal coordination with other USFS resources, and $6 \%$ of their time with USFS clients.

Range-cons and WL/F-managers stood out as having much more people and politically oriented tasks than foresters in their early USFS years $(p=.01)$. They were required to be more interdisciplinary in planning and management. The attitudes and skills necessary to be successful in these endeavors were mostly learned (by trial and error) on the job.

\section{USFS Values YPROS Do and Do Not Accept}

Much literature (e.g., Dalton 1950, Homans 1950, Miller 1967, Schein 1967, Gill and Bennis 1968) cites the common conflict between professional and organizational values of scientists in their employ. For example, chemists want to do theoretical research and their company only wants a lipstick that does not stain drinking containers; range managers want to collect needed browse impact data and agency administrators have them scheduled for months of meeting with the Forest planning team, etc.

The surprising cohesion of the USFS a generation ago (Gulich 1951, Kaufman 1960) was dependent upon USFS organizational values being consistent with foresters' professional values. If agency values are consistent with its professionals' values, there is likely high cohesion, productivity and esprite de corp-as Hall et. al (1970) Forest Service study noted. If there is value conflict, alienation and in-fighting often result.

What YPROS see as 2 most rewarded USFS values. In their own words YPROS identified the 2 most rewarded value/attitudes in the USFS. There was little disagreement in values stated by women and men-not so with different professionaltypes.

Table 2 presents the 2 values/attitudes professional recruits see as the first or second most rewarded by the USFS. The differences are statistically significant $(p=.05)$ even though all 3 professionaltypes stated "organizational loyalty" as the most rewarded. Now 
Table 2. What YPROS and SUPERS see as top attitudes/values most rewarded by the USFS".

\begin{tabular}{|c|c|c|c|c|}
\hline $\begin{array}{l}\text { Categories of Open-ended } \\
\text { Responses: }\end{array}$ & $\begin{array}{l}\text { Foresters } \\
(n=44)\end{array}$ & $\begin{array}{c}\text { Range- } \\
\text { cons } \\
(n=27)\end{array}$ & $\begin{array}{c}\text { WL/F } \\
\text { Biologists } \\
(n=38)\end{array}$ & $\begin{array}{c}\text { SUPERS } \\
(n=11)\end{array}$ \\
\hline 1. Production/work ethic & $28 \%$ & $16 \%$ & $27 \%$ & $28 \%$ \\
\hline 2. Get along with people & 10 & 12 & 11 & 22 \\
\hline 3. Good attitude/be flexible & 8 & 0 & 8 & 4 \\
\hline 4. Loyalty to USFS & 47 & 44 & 51 & 46 \\
\hline 5. Commitment to resources & $\mathbf{0}$ & $\mathbf{0}$ & 3 & $\mathbf{0}$ \\
\hline 6. Do quality work & 5 & 4 & 0 & $\mathbf{0}$ \\
\hline 7. Professional competence & 2 & 24 & 0 & 0 \\
\hline Totals: & $100 \%$ & $100 \%$ & $100 \%$ & $100 \%$ \\
\hline
\end{tabular}

${ }^{a}$ Chi square $=X^{2}=19.2$ with 10 degrees of freedom and significantly different at $5 \%$ for difference between professional-types.

observe the differences.

Range-cons were unique in giving open-ended responses that fit the professional competency category for values/attitudes they see as highly rewarded by the USFS (e.g., replies like "know your resource," "be able to contribute to multiple-use decisions in many area of expertise,"etc.). Few foresters and no WL/F biologist cited this category.

Foresters and WL/F biologists see the production or work-ethic as the next most rewarded USFS value/attitude. Getting along with people was also recognized as an important USFS value/attitude by all professional-types.

What SUPERS see as top two most rewarded USFS values. Recall that YPRO's immediate supervisors (SUPERS), another USFS generation with about 10 years permanent employment, were also surveyed. SUPERS were asked the identical question as YPROS on the "most rewarded USFS values/attitudes". The values/attitudes they saw as most rewarded are also shown in Table 2.

Somehow rewarded USFS values are being quickly and accurately communicated between the generations, for YPROS and SUPERS gave open-ended value responses that coded and ranked almost identically.

YPROS did give a much more diverse spread of values than SUPERS, and recall the that YPROS' perceptions differed by professional-type. Also note how rarely "commitment to the land/the resource" or "do quality work" are mentioned-values that natural resource students, their professors, and the USFS are supposed to cherish.

Most SUPERS (about 70\%) personally agree that the values/attitudes they cited as most rewarded are the ones that the USFS should reward. They also thought about two-thirds of the YPROS they supervise would also accept these as legitimate agency values. From the disagreement actually stated by YPROS (below), this SUPER perception appears a bit optimistic. Also notice that YPRO acceptance of the most rewarded USFS values/attitudes differ by professional-type (Table 3 ).

Recruits acceptance of most rewarded USFS values attitudes. After respondents described the 2 values/attitudes most rewarded by the USFS, they stated if they personally believe these are the proper values the agency should cherish. Range-cons were similar to foresters in over half accepting what they saw as the most rewarded USFS values (Table 3).

Almost twice as many WL/F biologists disagree with all 3 most rewarded USFS values than did range-cons or foresters. It appears that they find the USFS value system more inconsistent with their personal and/or professional values than foresters and range-cons. Gulick's (1951) and Kaufman's (1960) studies of the USFS, almost completely dominated by foresters (and men) in those days, cited no such conflict. As Leman (1981) has observed, their conclusions may have ignored some important internal value differences in the
Table 3. YPRO agreement and disagreement with three most rewarded USFS values/attitudes."

\begin{tabular}{|c|c|c|c|}
\hline $\begin{array}{l}\text { Disagree with any of most } \\
\text { rewarded USFS values: }\end{array}$ & $\begin{array}{l}\text { Foresters } \\
(n=44)\end{array}$ & $\begin{array}{l}\text { Range-cons } \\
(n=27)\end{array}$ & $\begin{array}{l}\text { WL/F biologists } \\
(n=38)\end{array}$ \\
\hline $\begin{array}{l}\text { 1. Accept all three } \\
\text { 2. Disagree with one } \\
\text { 3. Disagree with two } \\
\text { 4. Disagree with all three }\end{array}$ & $\begin{array}{l}51 \% \\
17 \\
20 \\
12 \\
\end{array}$ & $\begin{array}{c}56 \% \\
20 \\
8 \\
16 \\
\end{array}$ & $\begin{array}{l}31 \% \\
19 \\
25 \\
25 \\
\end{array}$ \\
\hline Totals: & $100 \%$ & $100 \%$ & $100 \%$ \\
\hline
\end{tabular}

${ }^{2} X^{2}=6.9$ with $6 \mathrm{df}$. and not significantly different at $5 \%$ level.

$1950 \mathrm{~s}$ - and then, much time, legislation, and USFS organizational change have occurred since the 1950's.

\section{Long-run Career Development}

Career development has been defined as an on-going process of fitting oneself into a profession and the USFS organization. Basic texts in career development (Hall 1976 and Schein 1978) present this process as passing through common stages. For example, Dalton et. al (1977) see 4 stages of professional career development. The Ginzberg et. al (1951) career model begins with a fantasy stage, then a tentative career choice stage, and ultimately realistic choice stages, as one settles into a long-term career choice. Women's career stages seem to share similarities (Henning and Jardim 1977) and differences (Gilligan 1979 and 1982) with those of men.

Our survey captured range-cons in the entry-stage of their professional and USFS career. Previous sections of the paper have shown how they are fitting into their first permanent job. The time frame of these questions was the past and present. The focus was $j o b$, the time dimension was short-run. This section focuses on YPROS career. The time dimension is long-run (the future).

Responses to two questions describe YPROS' current commitment to their career and the USFS: (1) do you have a long-term commitment to your profession, and (2) do you have a long-term commitment to the USFS organization? Responding with yes and no replies produced a $2 \times 2$ matrix:

Question: Do You Have a USFS CAREER Commitment? Yes No

Question:

Do You Have a

PROFESSIONAL

CAREER Commitment? No Type III Type IV

This matrix yields 4 types of long-term career commitment:

TYPE 1. Professional and USFS Commitment. YPROS committed to a career in both their profession and the USFS organization.

TYPE II. Professionally But Not USFS Committed. Professional commitment, but YPROS not yet committed to the USFS; they may or may not be ready to leave.

TYPE III. Committed to USFS Career But Not One's Profession. YPROS presently committed to a career in the USFS but not their professions.

TYPE IV. Searcher. Currently not fitting into a career in their profession or the USFS. May or may not be actually searching for alternatives.

The above types are generalizations or stereotypes. It will take more testing to see if a Type II YPRO might more strongly pursue a professional specialty (say range staff position) than a generalist, line administrative position (as Type I or III might). With these caveats, let's see how YPROS fit into these categories.

Fifty-two percent of range-cons were Type I (both USFS and professionally career committed), as were $57 \%$ of foresters and $35 \%$ of WL/F biologists. Many more WL/F biologists (49\%) were 
committed to a career in their profession but not the USFS (Type II) than forestcrs $(32 \%)$ or range-cons $(22 \%)$. Few were Type III (the stero-typed "organization man")- $4 \%$ range-cons, $5 \%$ WL/F biologists and no foresters were Type III. Range-cons had the greatest percent of Type IV (searchers) at $22 \%$-versus $11 \%$ for WL/F biologists and $11 \%$ for foresters. I'm unsure why twice the proportion of range-cons were Type III than their WL/F biologist and forester colleagues.

\section{Commitments to Career in Current Profession}

Range-cons and their colleagues have been practicing their professions less than 3 years. When asked, "If you could go back and begin your education again, what profession would you choose?", the large majority $(77 \%)$ would choose the same profession again. There was no difference between professional-types. Those who would choose another profession generally named one in some other natural resource field (e.g., a range-con who would be a forester).

Another set of questions further pursued career commitment: "If we define career as a 'long-term commitment to a profession,' have you made such a commitment to your profession? Most YPROS $(83 \%)$ believe they have made such a long-term professional commitment. Range-cons had the lowest percentage of professional commitment: $75 \%$ versus $89 \%$ for foresters and $84 \%$ for WL/F biologists. But these differences are not statistically significant ( $p \leq .05)$. A significantly lower percentage of women YPROS have made such a professional commitment-only $75 \%$ of women checked yes versus $92 \%$ of men $(p=.04)$. Women cited more uncertain spouse and family factors in their future that might complicate pursuit of their profession.

\section{Commitment to a Career in the USFS}

Recall that most YPROS had decided on their current profession at age 20 (mean). When making this choice, future USFS employment was much more important for range-cons (important for $77 \%$ ) and foresters ( $56 \%$ ) than for WL/F biologists (22\%). The USFS as a future employer was important to $62 \%$ of men YPROS in selecting their professional major in college, but to only $35 \%$ of women $(p=.07)$. For foresters and, especially, range-cons (and for men) a form of precommitment to becoming a USFS person may have existed for years.

When asked if they are currently committed to a career in the USFS, $56 \%$ of range-cons checked "yes". Fifty-seven percent of foresters and $40 \%$ of WL/F biologists checked "yes" (not a statistically significant difference at $p \leq .05$ ). Several questions explore USFS commitment further.

Like to Start Again in Another Organization? When asked, "If you could start your professional career over, what organization would you choose to work for? USFS or U_Different One." Thirty-seven percent of range-cons, able to turn back the clock, would start over in organization other than the USFS; $43 \%$ of WL/F biologists and only $19 \%$ of foresters would do so $(p<.01)$.

SUPER versus YPRO Commitment to USFS and Their Professions SUPERS were asked the identical 2 questions used to categorize YPROS into the 4 types of career commitment above. When the 2 generations of USFS professionals were compared, highly significant differences surfaced $(p<.01)$.

The overwhelming majority of SUPERS $(88 \%)$ were highly committed to both the USFS and their profession (Type I), versus only $48 \%$ of YPROS. Only $5 \%$ of SUPERS were professionally but not USFS committed (Type II), compared to 35\% of YPROS. SUPERS have a mean of 9 years in the USFS. Very few felt they had to give up their professional values and become administratively oriented, organization-people (only $4 \%$ of SUPERS fell in Type III). By that time in their careers few SUPERS were searchers (3\% were Type IV), compared to $14 \%$ of YPROS.

When SUPERS were in the entry-stage of their professions and the USFS, like the YPROS they supervise, they may also have had doubts and uncertainties about their professional and agency commitments. They don't now. Most SUPERS (88\%) see little or no conflict between their professions and the USFS, and are committed to both (i.e., they are Type I). Studies of Catholic priests (Hall and Schneider 1972) and USFS managers (Hall et al. 1970) found organizational loyalty tends to increase with tenure-and as a dissidents exit. The latter study also found USFS professionals believing in values that were esteemed by the USFS (e.g., service to the public) were bonded tighter to the agency than those who had personal values not highly valued by the Forest Service.

\section{Some Closing Comments}

The range-cons we've examined were more like foresters than $\mathrm{WL} / \mathrm{F}$ biologists. Their initial career and agency motivations centered on geographic preference and practical occupational rewards versus WL/F-biologists'more idealistic orientation). As students, range-cons dreamed more of becoming future USFS employees. They tended to accept the USFS value system and, after 1-3 years in the agency, most had a long-term commitment to stay there. They were also unique in the relatively large percentage citing professional competence as a reward USFS attitude/value. That is, they judged their professional expertise was considered, valued, and rewarded by the agency.

The USFS has hired foresters and range-cons on a regular basis longer than WL/F biologists; these more established professionaltypes have been much more influential in shaping the organizational cultures of Regions 4 and 6 . In addition, range-cons and foresters have been employed for decades because the agencies thought it appropriate. WL/F biologists were hired in the 1970s in response to external social and legislative pressures. This may help explain why range-cons and foresters are finding it less difficult than their WL/F biologist colleagues to fit into authority relationships, organizational values, and a long-term USFS career. Although the majority of all YPROS are fitting into the USFS organizational culture, twice the proportion of WL/F biologists (about $25 \%$ ) are not. These differences usually remained when professional-types were controlled for sex differences.

The focus of this paper on fitting into the USFS culture in no way means I believe professional recruits should do all the adapting and, without regard to professional values and standards, become company yes-men or yes-women. The challenge for professional recruits is to find an acceptable balance between commitment to one's profession and to the agency. This has always been a central adjustment issue for academically socialized and educated professional recruits trying to become satisfied, productive members of the "real world."

Adjusting from "ivy tower" academic life to the realities of bureaucracies was often a stressing transition for the young natural resource managers studied. Their college experiences usually centered on the mythic-hero quest for the right answer. Their academic problem-solving was largely an individual effort-the student, the problem, the theory/models, the data, the solution. There is little team work and dealing with the library was likely the biggest bureaucratic encounter in the process. In the world of bureaucratic organizations, the quest for and approval of acceptable solutions is a group effort. Since the environmental legislation of the 1970 s, with increased interdisciplinary and public involvement, natural resource management is even more a group negotiation process. This makes it even more critical that range-con students be better educated and role modeled to understand, appreciate, and master the internal politics of decision-making-so they can find satisfying and productive careers in the "real world" of natural resource agencies.

If we professionals care about the condition of resources that range-cons manage, we had better care about the condition of their careers-studying their career development professionally and empirically. For I believe natural resources can only be managed well by men and women who feel okay with their profession, 
themselves, and the agency for which they work.

\section{Literature Cited}

Akins, B., M. Glazer, and T. Marine. 1982. 1981 Work Force Planning Data Book. Personnel Manage. Staff. USDA-Forest Service, Washington, D.C.

Arnold, R.K. 1970. Changing educational needs for research, teaching, and extension. J. Range Manage. 23:330-33.

Box, T.W. 1974. Trends in range management education. J. Range Manage. 17:237-41.

Cook, C.W., and C.D. Bonham. 1974. An analysis of range conservation academic training. J. Range Manage. 27:480-83.

Dalton, M. 1950. Conflicts between staff and line managerial officers. Amer. Sociological Rev. 15:342-51.

Dalton, G.W., P.H. Thompson, and R.L. Price. 1977. The 4 stages of professional careers. Organizational Dynamics 6:19-42.

Gill, P.P., and W.G. Bennis. 1968. Science and management: two cultures? J. Appl. Beh. Sci. 4:75-108.

Gilligan, C. 1979. Women's place in man's life cycle. Harvard Educ. Rev. 49:431-45.

Gilligan, C. 1982. In a different voice. Harvard Univ. Press. Cambridge, Mass.

Ginzberg, E., J.W. Ginzberg, S. Axelrad, and J.L. Herma. 1951. Occupational choice. New York: Columbia Univ. Press.

Gulick, L.H. 1951. American forest policy. New York: Duell, Sloan, and Pearce.

Hall, D.T. 1976. Careers in organizations. Goodyear Publishing Co. Santa Monica, Calif.

Hall, D.T., and B. Schneider. 1972. Toward specifying the concept of work climatic study of Roman Catholic diocesan priests. J. of Appl. Psyc. 56:447-85.

Henning, M., and A. Jardim 1977. The managerial women. New York: Anchor Press/Doubleday.

Homans, G.C. 1950. The human group. New York: Harcourt Brace.
Kaufman, H. 1960. The forest ranger. Baltimore, Md.: Johns Hopkins Press.

Kennedy, J.J., and J.A. Mincolla. 1982. Career evolution of young 400Series U.S. Forest Serv. professionals (Career Development Project Report 1) College of Natural Resources, Utah State Univ., Logan.

Kienast, C.R., and C.J. Scifres. 1973. Survey of professional attitudes toward range science education and training. J. Range Manage. 26:161-64.

Leman, C.K. 1981. The forest ranger revisited: administrative behavior in the 1980s. Paper at annual meeting of Amer. Pol. Sci. Ass. New York, NY.

Levinson, D.J. et al. 1978. The seasons of a man's life. New York: Ballantine Books.

Miller, G.A. 1967. Professionals in bureaucracy: alienation among industrial scientists and engineers. Amer. Sociol. Rev. 32:755-67.

Mincolla, J.A., and J.J. Kennedy, 1982. Conceptual foundation for career development survey of U.S. Forest Service professionals and their supervisor (Career Development Project Pub. 2) College of Natural Resources, Utah State University, Logan.

Morris, M.W. 1961. Range management as a profession. J. Range Manage. 14:3-5.

Norton, B.E., and J.N. Eastmond, Jr. 1981. Guiding a range-curriculum with an educational needs assessment. J. Range Manage. 34:475-79.

Schein, E.H. 1967. Attitude change during management cducation: a study of organizational influence on student attitudes. Adm. Sci. Quart. $11: 601-28$.

Schein, E.H. 1978. Career dynamics: matching individual and organizational needs. Reading, Mass..: Addison-Wesley.

Tisdale, E.W. 1956. Range management education. J. Range Manage. 9:218-19.

Vaillant, G.E. 1977. Adaptations to life. Boston, Mass.: Little, Brown, and Co.

Van Maanen, J.(ed). 1977. Organizational careers: some new perspectives. New York: John Wiley and Sons.

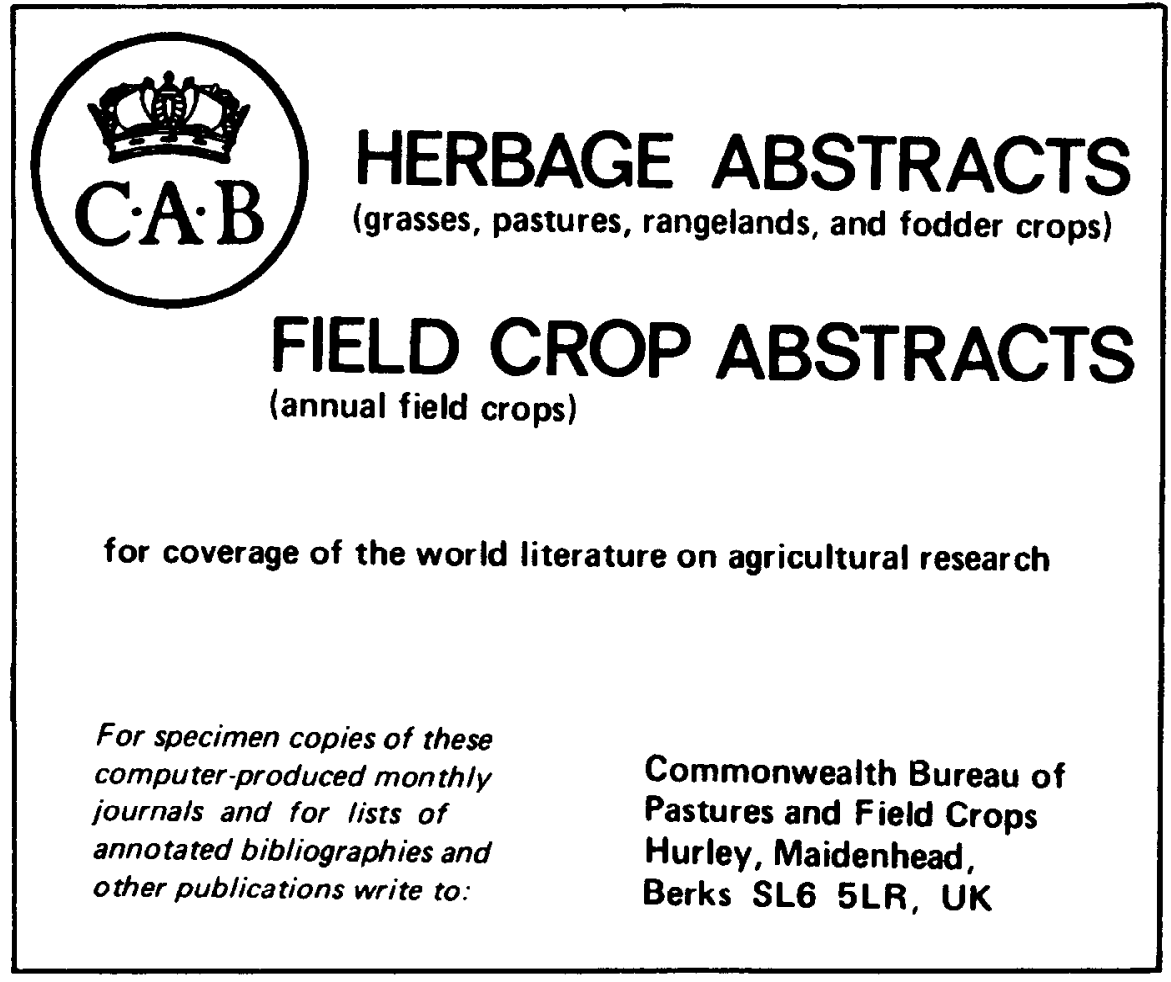

